\title{
¿Ilusión o realidad? El disfraz en las comedias de Marivaux
}

\section{Illusion or reality? Costumes in the comedies of Marivaux}

\author{
Carolina Fernández Correjes \\ Universidad de Valladolid \\ carolina.correjes@gmail.com
}

\begin{abstract}
The analysis of costume shows the complexity of connection between the true and the false character's identity in Marivaux's comedies. It's therefore interesting to study the object's potentialities to help tell the story, change the character's identity and discover love. An object can transform the character's identity. Consequently, the main aim of this work is to provide a general analysis of the sixteen comedies in which Marivaux employs costume on the basis of Anne Ubersfeld's definition in order to describe its functions and meanings.
\end{abstract}

\section{Key-words}

comedie, Marivaux, costume, functions, objects.

\begin{abstract}
Résumé
L'exploitation du déguisement montre l'extrême complexité des rapports entre l'être et le paraître dans les comédies marivaudiennes. Par conséquent, il est intéressant d'étudier le pouvoir du déguisement pour déclencher l'intrigue, créer ce double jeu du faux et du vrai et révéler les sentiments des personnages. Un objet suffit pour transformer l'identité des personnages. Pour cela, à travers la définition d'objet théâtral proposée par Anne Ubersfeld nous allons analyser les seize comédies où Marivaux utilise les objets pour déguiser les personnages et conduire l'action.
\end{abstract}

\section{Mots-clés}

comédie, Marivaux, déguisement, fonctions, objets. 
Anales de Filología Francesa, n. ${ }^{\circ} 28,2020$

¿ILUSión o REALIDAD? El DisfraZ EN Las COMEdias de MarivauX

\section{Introducción}

Como es bien sabido, Marivaux es el dramaturgo de la primera mitad del siglo XVIII que más lejos fue en el camino renovador de la comedia. Su producción teatral, al igual que la escritura periodística y novelesca, gira en torno al comportamiento del ser humano, línea central del pensamiento de Les Modernes. A grandes rasgos, su originalidad reside en superponer elementos de la Commedia dell'Arte a las convenciones heredadas del teatro clasicista ${ }^{1}$, interiorizar el conflicto (R. Pomeau, 1971: 194) y hacer que la acción avance por la presión de unos personajes sobre otros, a través de las situaciones creadas y a través de sus palabras (F. Deloffre \& F. Rubellin, 2000: 8-9), lo que J. Rousset (1989) identifica como la estructura del doble registro.

Sin embargo, contrariamente a otros autores de su época, como Beaumarchais o Diderot, que escriben sobre sus obras y sobre la creación de las mismas², "Marivaux n'a pas laissé d'ouvrage didactique: ce que l'on sait des conseils qu'il a donnés provient des confidences de ses comédiens ou de son texte lui-même”, (P. Peyronnet, 1974: 56). El autor se atreve a alejarse del molde cómico creado por Molière, indiscutido hasta entonces para la comedia francesa, elaborando progresivamente su propio sistema dramático (F. Deloffre \& F. Rubellin, 2000: 10). Y uno de los elementos a los que recurre de forma habitual es el disfraz, recurso que utiliza con maestría desde su primera comedia, Le Père prudent et équitable (1712):

Ce déguisement dont Marivaux fait un emploi si fréquent. Trouvera-t-on un dramaturge qui en use et abuse autant que lui? La persistance d'un tel procédé ne peut manquer de signification. Il ne captiva pas seulement les spectateurs des comédies, il les contraint aussi à réfléchir - et ce sont des réflexions sur les hommes. (D’Hondt, 1991: 95)

A pesar del interés que suscita la utilización del disfraz en sus comedias, como demuestran, entre otros muchos, los trabajos de H. Duchêne, P. Lambert, R. Pomeau, J. D'Hondt o J. Jiménez-Salcedo, no encontramos estudios específicos sobre los objetos que Marivaux utiliza para ocultar la identidad de los personajes que sistematicen su función y sentido en el conjunto de la producción teatral de autor. En consecuencia, nuestro objetivo es analizar las dieciséis comedias en las que Marivaux recurre al uso del disfraz, identificar los objetos

1 R. Pomeau definió a Marivaux como "le dernier en date des classiques de la scène française" (1974: 267).

2 Otros autores ponen en evidencia la ausencia de escritos sobre el teatro en la producción de Marivaux. T. Nakayama señala que "Marivaux, homme discret, n'a pas rédigé de théorie du théâtre et n'a presque jamais attaché de préface à ses pièces. Il nous est difficile de connaître sa conception des rapports entre l'improvisation et le texte. Cependant, sa dernière pièce Les Acteurs de bonne foi dont le sujet même est le théâtre, pourrait nous servir à deviner ses idées sur le théâtre", (T. Nakayama, 2002: 25). Por su parte, D. Trott afirma que "Comme les grands dramaturges Shakespeare et Molière avant lui, Marivaux ne laissa pas, ou peu, de manuscrits sur son théâtre. [...] les pièces de Marivaux (plus que beaucoup d'autres) nous obligent à trouver les échos de leur production dans leur texte écrit" (D. Trott, 2000: 207). 
que utiliza para tal fin y dar una visión general de sus funciones y significados a través de ejemplos concretos. Nuestro corpus de análisis es el siguiente:

1. Le Père prudent et équitable ou Crispin l'Heureux Fourbe (1712)

2. La Double Inconstance (1723)

3. Le Prince travesti (1724)

4. La Fausse Suivante ou Le Fourbe Puni (1724)

5. Le Dénouement imprévu (1724)

6. L'Île des esclaves (1725)

7. Le Triomphe de Plutus (1728)

8. Le Jeu de l'amour et du hasard (1730)

9. Le Triomphe de l'amour (1732)

10. L'École des mères (1732)

11. La Méprise (1734)

12. La Mère confidente (1735)

13. La Joie imprévue (1738)

14. L'Épreuve (1740)

15. La Commère (1741)

16. La Femme fidèle (1755)

Para tal fin, es indispensable realizar, en primer lugar, una breve reflexión teórica sobre el lugar que ocupan los disfraces en la representación teatral.

T. Kowzan en su artículo "Le signe au théâtre. Introduction à la sémiologie de l'art de le spectacle", publicado en la revista Diogène (1968), dio un gran paso al definir el signo teatral e identificar trece sistemas de signos en teatro: la palabra, el tono, la mímica, el gesto, el movimiento, el maquillaje, el peinado, el traje, los accesorios, el decorado, la iluminación, la música y el sonido. Como vemos, T. Kowzan considera que el traje de los actores y los accesorios $^{3}$ son sistemas independientes. Sin embargo, por su parte, P. Pavis, defiende que los límites entre la ropa del personaje y los objetos que contribuyen a caracterizarlo (o, en nuestro caso, disfrazarlo) no están bien definidos:

Il n'est pas si facile de dire où commence le vêtement, et il n'est guère plus aisé de distinguer le costume d'ensembles plus localisés comme les masques, les perruques, les postiches, les bijoux, les accessoires ou le maquillage. C'est une opération délicate que d'extraire le costume de l'ensemble de l'acteur dans son milieu. Ce qu'on gagne alors dans la précision des analyses des vêtements, on risque de le perdre dans l'évaluation de leur impact sur le reste de la représentation. (Pavis, 2005: 160)

3 Si retomamos los trece sistemas de signos propuestos por T. Kowzan (1997), encontramos que el autor utiliza la palabra accesorio en vez de objeto. En el plano puramente lexical, el adjetivo "accesorio" significa "secundario" y es, por tanto, antónimo de "esencial”. Así pues, muchos teóricos del teatro, entre ellos A. Ubersfeld, han preferido dejar de utilizar el término "accesorio" en beneficio del término "objeto teatral", que nosotros utilizaremos. 
Por lo anteriormente explicado, decidimos recurrir a la definición de objeto teatral que propone A. Ubersfeld. Según la autora, toda cosa que figura sobre la escena y es manipulada por los actores adquiere ipso facto el carácter de objeto teatral: el objeto teatral es una cosa, retomada y recompuesta por la actividad teatral: todo lo que está en el escenario, incluso un elemento puesto de forma casual, se vuelve significante por su sola presencia dentro del universo escénico (Ubersfeld, 1996: 61). Además, la primera condición necesaria para que un objeto teatral sea considerado como tal es que se encuentre inscrito, implícita o explícitamente, en el texto de la obra, es decir, en los diálogos y/o en las didascalias ${ }^{4}$ (Ubersfeld, 1993: 138). Así pues, en nuestro análisis consideraremos como disfraz todo objeto que sirva para ocultar la identidad de los personajes, incluida la vestimenta. Sin embargo, evitaremos tomar el discurso textual como homólogo del discurso escénico ya que a un lexema-objeto textual no le va a corresponder siempre un lexema escénico, pues hay objetos nombrados en el texto que no aparecen luego en escena, lo que M. Vuillermoz denomina objetos extraescénicos (Vuillermoz, 2000: 49). Así pues, en el presente estudio, analizaremos los objetos teatrales escénicos que sirvan para ocultar la identidad de los personajes. Parece obvio, pero no lo es tanto, dada la época que nos ocupa.

En el momento en que Marivaux llevó a escena sus comedias, son los propios comédiens los que se encargan generalmente del vestuario que utilizan durante la obra y, aunque pueda parecer extraño desde la perspectiva de un espectador actual, éste no se correspondía, en la mayoría de los casos, con el personaje que interpretaban. Su elección no responde a un deseo de caracterización del personaje, nada más lejos, sino que depende de las posibilidades económicas del actor en cuestión y/o de la compañía para la que trabajaba y de las convenciones de la misma. En consecuencia, la preocupación por conferir una armonía estética a la obra es casi inexistente, hecho que se constata en la falta de coordinación en el vestuario de los actores que desempeñan el mismo papel en la obra o papeles contrarios. La situación se agrava aún más, si cabe, con la tendencia de algunos actores que gozaban de la protección de grandes señores, fundamentalmente los de la Comédie-Française, a llevar en el escenario los fastuosos trajes con los que los agasajan. Su único propósito era suscitar la admiración del público, sin importarles el personaje que representaban en la obra: "Voulant paraître au-dessus de leurs camarades, portant des vêtements de ville ordinaires [...] les titulaires des premiers rôles portent avec orgueil des habits donnés par les grand seigneurs qui s'intéressent à eux" (Peyronnet, 1974: 84).

A pesar de todas las dificultades señaladas, el público es capaz de identificar a los personajes, incluso si hay juegos escénicos de disfraces, gracias a los diálogos, pues el texto confirma y refuerza su identidad, o mediante detalles materiales aparentemente insignificantes, como pueden ser los objetos (Pavis, 1986: 28).

4 Preferimos utilizar el término "didascalias" y no "acotaciones", entendiendo que las acotaciones están incluidas en las primeras: "La didascalie comprend donc tout ce qui permet de déterminer les conditions d'énonciation du dialogue", (Ubersfeld, 1996: 28-31). 
Llegados a este punto, se hace necesario posicionarse sobre otorgar la preeminencia en nuestra investigación al texto o a la representación. Como afirma C. Bobes Naves, "acceder al texto para realizar el análisis de la obra que queremos estudiar suele ser asequible, sin embargo, la representación resulta, la mayor parte de las veces, imposible" (1988: 75). Ante las dificultades materiales que nos encontramos - por desgracia, no tenemos apenas documentos de la puesta en escena de las comedias marivaldianas, salvo algunas pinturas o grabados de Bertall o Watteau, y la inexistencia de la figura del director de escena en el siglo XVIII hace que sea muy difícil reconstruir, hoy en día, las escenificaciones de la época (Peyronnet, 1974)-, centraremos nuestro estudio sobre los objetos escénicos ${ }^{5}$ cuya función sea enmascarar la identidad de los personajes en el texto teatral (diálogos y didascalias) que nos legó el autor, teniendo en cuenta su contexto de producción y puesta en escena, es decir, en la primera mitad del siglo XVIII.

\section{Los disfraces marivaldianos, objetos y funciones}

La fórmula teatral que Marivaux utiliza por excelencia en sus comedias es "ce jeu du faux et du vrai" (Ramos Gómez, 2009: 287). En principio, la indumentaria sirve para catalogar a los personajes según las normas sociales del momento, lo cual permite a los espectadores reconocerlos. Los disfraces se apoyan en este mecanismo, falseando la lectura que el otro personaje realiza sobre los signos de reconocimiento. Es el doble valor del atuendo capaz de reflejar la verdadera identidad del personaje o de enmascararla, aunque sea temporalmente (H. Lafon, 2012: 37). Marivaux convierte la indumentaria del personaje en el hilo conductor de la acción cuando los personajes la manipulan a su antojo para conseguir sus objetivos, dando lugar a múltiples juegos escénicos.

Le travestissement est indissociable de la figure de Marivaux. L'histoire littéraire a conservé les représentations de personnages bouleversant l'ordre social de l'Ancien Régime par le biais d'une série de déguisements, notamment celui du maître en valet et vice versa. Par ailleurs, les croisements d'identités, dont le théâtre de l'époque était si friand, procurent des situations de quiproquo amusantes et carnavalesques (JiménezSalcedo, 2008: 173)

5 M. Vuillermoz subraya la dificultad de distinguir categóricamente los objetos escénicos y extraescénicos : “ En effet, les uns et les autres ne diffèrent ni par leur nature [...] ni par leur fonction dramatique [...] Mais la raison principale qui empêche de distinguer trop catégoriquement les deux classes d'objets tient au fait que les objets scéniques ne le sont en réalité que momentanément, dans la mesure où une partie plus ou moins longue de leur 'histoire' se déroule hors de la scène. Pour qu'un objet puisse être exclusivement scénique, il faut en effet qu'il soit créé, utilisé et détruit sur scène, dans un segment temporel continu”, (M. Vuillermoz, 2000: 51-52). En la presente investigación, consideramos que un objeto es escénico si aparece, al menos, una vez en escena. Si los personajes se refieren a dicho objeto que ha aparecido en escena en ocasiones en las que no está presente, dichas referencias no podríamos contabilizarlas como objetos extraescénicos. El objeto extraescénico, por su parte, no se materializa nunca. 
Si recordamos los tres tipos de disfraz propuestos por G. Forestier (1988) -verbal (ou d'affirmation), d'apparence (ou de costume) et ostensible- comprobamos que las comedias marivaldianas presentan mayoritariamente disfraces de apariencia, entre los que destacan los cambios de identidad, sexo, o condición (Nakayama, 2001: 28).

Il va de soi qu'un déguisement de costume, un travestissement, un masque, une dissimulation volontaire d'identité et une ignorance d'identité ne relèvent pas d'un même type d'élaboration et engagent des mises en œuvre différenciées. Mais ces différences sont loin d'être de même nature. (Forestier, 1988: 43)

Por tanto, la voluntad de engañar al otro se ejerce fundamentalmente en dos niveles, cambio de sexo y cambio de condición social (Lafon, 2012: 69-70). En las comedias de Marivaux, las mujeres se convierten en hombres y los hombres en mujeres para conseguir sus propósitos: "Marivaux exprime ainsi un changement d'identité des personnages bien ancré dans la tradition littéraire du XVIII ${ }^{\mathrm{e}}$ siècle: le travesti devient un Autre, mais cet Autre, appartenant au sexe opposé, conserve des signes de sa première identité" (Jiménez-Salcedo, 2008: 173). Asimismo, mediante el uso del disfraz, los señores pueden convertirse en criados y viceversa. El motivo que justifica que los señores cambien su condición es, en la mayoría de los casos, el amor, mientras que el uso del disfraz por parte de los criados responde fundamentalmente a su intento de ayudar a los señores.

Como veremos a continuación, el dramaturgo pone especial atención en señalar, mediante las didascalias y también mediante las réplicas de los personajes, que éstos ocultan su identidad, de manera voluntaria o no. Las didascalias que han retenido nuestra atención son las didascalias de objeto. M. Vuillermoz denomina así a toda didascalia que exige, directa o indirectamente, la presencia escénica del objeto u objetos que en ella se mencionan o implica su manipulación. Por otra parte, las informaciones metateatrales pueden ser transmitidas, mediante didascalias implícitas, contenidas dentro del texto dialogado (Vuillermoz, 2000: 38-39). De ahí la importancia de descifrar los diálogos: en el texto, es el lector quien debe descubrir, a través de las palabras de los personajes, la existencia escénica del disfraz mientras que, dentro del universo de la puesta en escena, serán los propios personajes mediante sus réplicas los que se encarguen de señalar que su identidad o la de otros es fingida. Los objetos que aparecen en las réplicas pueden ser escénicos y extraescénicos mientras que en las didascalias sólo son escénicos.

Los objetos utilizados a modo de disfraz que aparecen tanto en diálogos como didascalias son escasos y no son descritos con precisión. En las raras ocasiones en las que el dramaturgo nos facilita alguna información, es para llamar nuestra atención sobre el objeto en cuestión. Se relacionan, en general, con la vida cotidiana, por lo tanto, el espectador contemporáneo es capaz de identificarlos sin dificultad. A grandes rasgos, son los siguientes: ropa (atuendo de caballero, librea, delantal y domino), complementos (espada, funda, cin- 
turón, máscaras y botas) y otros objetos (botellas y barbas postizas). Todas las comedias de Marivaux en las que los personajes ocultan su identidad requieren al menos, la presencia de un objeto en escena, siempre supeditada a las necesidades de la intriga.

Muchos han sido los autores que han intentado realizar una clasificación las comedias marivaldianas, destacando a Roger Guichemerre (1978) o F. Deloffre y F. Rubellin (2000), sin embargo, la dificultad es evidente: "Il en est finalement de ses comédies comme de ses héroïnes, toutes différentes et toutes semblables", (R. Pomeau, 1971: 186). Lo mismo podríamos sobre las funciones del disfraz. A nuestro parecer, resulta complicado establecer límites claros, pues tiene la capacidad de resemantizarse a lo largo de la obra y de acumular varias funciones. P. Lambert (1973) abordó la confrontación entre ser y parecer en la que se basa el teatro de Marivaux en su obra Réalité et ironie. Les jeux de l'illusion dans le théâtre de Marivaux, y señaló las diferentes funciones del disfraz en las comedias en las que aparece. Tomando como punto de partida su estudio y el de H. Lafon (2012) sobre los objetos en la novela francesa del siglo XVIII, consideramos que, en las comedias marivaldianas, el disfraz da nuevas posibilidades a quien decide usarlo, permitiéndole, esencialmente, entrar donde no debe, conocer a los demás con mayor libertad, poner a prueba el amor y dar una lección moral a otro personaje. A continuación, analizaremos las comedias en las que predomina cada una de las funciones y focalizaremos nuestra atención en los objetos que el autor utiliza para disimular la identidad de los personajes.

\subsection{Entrar donde no se debe}

Los disfraces son el subterfugio que los personajes principales utilizan a menudo para superar los obstáculos que se erigen ante ellos. El disfraz permite al que lo lleva no afrontar el obstáculo directamente, evitarlo o rodearlo y ofrece múltiples posibilidades a quien lo usa. Gracias a la identidad fingida, el personaje puede entrar donde no debe. Encontramos dos comedias en las que el uso del disfraz responde a esta función, Le Triomphe de l'amour (1732) y L'École des mères (1732).

La princesa Léonide se disfraza de hombre y se hace pasar por un joven estudioso en Le Triomphe de l'amour (1732) para introducirse en la mansión de Hermocrate, donde vive recluido su amado, Agis. La acompaña su sirvienta, también disfrazada de hombre, lo sabemos a través de una didascalia: "Léonide, sous le nom de Phocion; Corinne, sous le nom d'Hermidas", (I, 1). Su propósito es devolver el trono usurpado a Agis, legítimo descendiente de Cleomène, de quien además se ha enamorado. No puede utilizar su verdadera identidad, pues Hermocrate no le permitiría acercarse al joven y éste la rechazaría de inmediato ya que Hermocrate y su hermana Léonide "n'ont travaillé qu'à lui inspirer de l'aversion pour moi, qu'à me peindre sous les traits les plus odieux, et le tout sans me connaître, sans savoir le fond de mon âme" (I, 1). El disfraz origina un triple enredo 
amoroso, pues los hermanos Hermocrate y Léontine y el Príncipe Agis se enamoran de la misma persona, Agis y Hermocrate de Aspasie y Léontine de Phocion, sin embargo, todos ignoran su verdadera identidad.

La primera en rendirse a su poder es Léontine. La Princesa, bajo el disfraz de Phocion, le ordena a su criada, disfrazada de hombre también, que le entregue el retrato de la solterona delante de la propia Léontine, fingiendo que cumple un encargo de su amo y que le interesa saber su opinión sobre la miniatura que le ha mandado pintar: Léontine se interesa por la miniatura ("Peut-on le voir avant qu'on l'emporte?") y, cuando descubre, asombrada, su imagen, no puede evitar devolvérselo a Phocion como prueba de su amor (II, 7).

Al mismo tiempo, la Princesa se hace pasar por una noble, llamada Aspasie, ante Hermocrite y Agis, aunque se inventa una justificación de su disfraz distinta para cada uno. Al filósofo le dice que se ha enamorado de él y, conociendo su actitud ante el amor, busca en su disfraz un medio para poder acercarse. Utiliza la misma táctica que con su hermana, mostrándole en el momento oportuno y con la ayuda de sus cómplices, en esta ocasión, Arlequin, un retrato en miniatura de cada uno que ha mandado hacer expresamente y le entrega el suyo, prueba de amor irrefutable. Siguiendo con su estrategia, a Agis le hace creer que es una dama que oculta su identidad para huir del matrimonio que la Princesa quiere concertar con uno de sus parientes: "cet habit vous abuse, il vous cache une fille infortunée qui échappe sous ce déguisement à la persécution de la Princesse. Mon nom est Aspasie: [...] et je n'ai trouvé d'autre ressource contre cette violence que de me sauver sous cet habit qui me déguise"(II, 3).

Decididos a casarse clandestinamente, el filósofo y Léontine se reúnen para despedirse y, se dan cuenta, al mostrarse los retratos de sus amantes, de que los han engañado: las imágenes de las miniaturas corresponden a la misma persona. Finalmente, la princesa devuelve el trono a Agis, enamorado de ella, lo cual hubiera sido imposible sin su disfraz: "je voulais rendre le trône à Agis et je voudrais être à lui. Sous mon nom j'aurais peut-être révolté son cœur, et je me suis déguisée pour le surprendre; ce qui n'aurait encore aboutit à rien, si je ne vous avais pas abusés vous-mêmes", (III, 11).

En L'École des mères (1732), Éraste consigue entrar en la casa de su amada Angélique para poder ver a la joven, a la que la señora Argante quiere casar con otro hombre, cambiando sus ropajes nobles por una librea de lacayo: "Éraste, sous le nom de La Ramée et avec une livrée" (esc. I). Logra su propósito gracias a la ayuda de sus cómplices, los criados Frontin y Lisette, de la que dice ser pariente: Sin embargo, el disfraz esconde su rango, pero no sus maneras nobles, como dice la criada: “ Oui, vous voilà fort bien déguisé, et avec cet habit-là, vous disant mon cousin je crois que vous pouvez paraître ici en toute sûreté ; il n'y a que votre air qui n'est pas trop d'accord avec la livrée" (esc. I). Éraste acude con Frontin a entregarle a su amada una efusiva carta en la que le expresa su dolor ante el inminente 
matrimonio de la joven, matrimonio concertado por su madre, que hace vivir a Angélique prácticamente recluida, lo cual les impide tener la ocasión de encontrarse a solas para poder hablar libremente. Angélique no lo reconoce y se expresa espontáneamente, sin tener que controlarse, como ocurriría si supiera que Éraste está presente:

Lisettte. Prenez donc une bonne résolution de n'être pas à un autre. Il y a ici un domestique à lui qui a une lettre à vous rendre de sa part.

Angélique, charmée. Une lettre de sa part! Eh! Tu ne m’en disais rien! Où est-elle? Oh, que j'aurai de plaisir à la lire! donne-moi-la donc! Où est ce domestique? (esc. VII).

La carta reafirma lo que siente Angélique por Éraste, provocando una reacción afectiva tanto en Angélique al leerla como en Éraste al escucharla, que se descubre y se arrodilla ante ella, pidiéndole que recapacite sobre su matrimonio.

Por su parte, el señor Damis, padre de Éraste, decepcionado, pues había puesto mucha ilusión en el que pensaba que iba ser el último matrimonio de su vida, decide averiguar quién es el otro pretendiente de Angélique, que no es otro que su propio hijo. Con la ayuda de Frontin, se disfraza con un domino ${ }^{6}$ - como hay invitados en la casa de la señora Argante que quieren disfrazarse después de cenar para pasar un rato divertido, Frontin coge un domino de los que han mandado traer-y se esconde en la habitación en la que se van a encontrar a oscuras Angélique y Éraste:

Frontin. Vous avez raison; attendez, quelques amis de la maison qui sont là-haut, et qui veulent se déguiser après souper pour se divertir, ont fait apporter des dominos qu'on a mis dans le petit cabinet à côté de la salle, voulez-vous que je vous en donne un? Monsieur Damis. Tu me feras plaisir. (esc. XIII)

El padre de Éraste se disfraza y se esconde a esperar la llegada de los amantes. Su hijo llega primero y, creyendo que es su amada la que está en la habitación, le declara su amor. El señor Damis, perplejo al comprobar que su rival es, en realidad, su hijo, decide quedarse a escuchar. Al momento llegan Lisette y Angélique. Éraste continúa la conversación que creía haber empezado con la muchacha y aparece en escena la señora Argante con Frontin, que presencia cómo su hija declara su amor a Éraste y se queja de su inexperiencia en el amor, resultado de la estricta educación que ha recibido por parte de su madre, basada en la sumisión y en la falta de libertad para expresar tanto sus opiniones como sus sentimientos. Encolerizada, le pide a Frontin que encienda las luces y confunde al señor Damis, enmascarado aún, con su hija, a la que amenaza con encerrar en un convento. El señor Damis se quita divertido la careta y descubre su verdadera identidad y la de su hijo:

6 Según el diccionario Le Nouveau Petit Robert (2002): “Domino: Costume de bal masqué consistant en une robe flottante à capuchon". 
Mosieur Damis, démasqué, à Madame Argante, et en riant. Vous voyez bien qu'on ne me recevrait pas au couvent.

Madame Argante. Quoi! c'est vous, Monsieur? (Et puis voyant Éraste avec sa livrée.) Et ce fripon-là, que fait-il ici? Monsieur Damis. Ce fripon-là, c'est mon fils, à qui, tout bien examiné, je vous conseille de vous donner votre fille (esc. XIX)

Después de lo que el disfraz le ha permitido escuchar, el padre de Éraste está de acuerdo en que su hijo y Angélique se casen, consiguiendo que la señora Argante también acepte el matrimonio: "allons, Monsieur, je suivrai vos conseils, et me conduirai comme il vous plaira”, (esc. XIX).

\subsection{Conocer a los demás y darse a conocer con mayor libertad}

En ocasiones, el disfraz permite a los personajes conocer a los demás y darse a conocer en tanto que individuo, sin que interfiera el prestigio del propio rango o sin los prejuicios que conllevaría la propia identidad, por ocupar una posición subalterna ante la cual no tienen por qué desear causar una buena impresión, por tanto, se muestran tal y como son. Ser amado por lo que uno es como persona, independientemente de la posición o la fortuna, es un deseo frecuente de los personajes marivaldianos, que da sentido a la acción de cuatro de las comedias de Marivaux en las que aparecen disfraces: "Marivaux trascende la démarche de séduction pour présenter le travestissement comme le moyen de reconnaissance de l'amour" (Jiménez-Salcedo, 2008: 176).

En La Double Inconstance (1723), Silvia, a pesar de creerse enamorada de Arlequin, se siente atraída por un oficial de palacio que la ha visitado en varias ocasiones, que no es otro que el Príncipe disfrazado, que quiere casarse con ella, pero sin imponer el matrimonio: “je la rencontrai près de sa maison; j'avais soif, elle alla me chercher à boire: je fus enchanté de sa beauté et de sa simplicité, et je lui en fis l'aveu. Je l'ai vue cinq ou six fois de la même manière, comme simple officier de palais" (I, 2). Sin desvelar su identidad, la lleva a palacio en nombre del Príncipe y la colma de atenciones, a pesar de lo cual la joven, enamorada de Arlequin, rechaza el matrimonio principesco:

Silvia. Qui est-ce qui lui a dit de me choisir? M'a-t-il demandé mon avis? S'il m'avait dit: Me voulez-vous, Silvia? je lui aurais répondu: Non, Seigneur, il faut qu'une honnête femme aime son mari, et je ne pourrais pas vous aimer. Voilà la pure raison, cela, mais point du tout, il m'aime, crac, il m'enlève, sans me demander si je le trouverai bon. Trivelin. Il ne vous enlève que pour vous donner la main. (I, 1)

El Príncipe ordena entonces llevar a palacio también a Arlequin, siguiendo los consejos de su confidente Flaminia, que concibe un plan para lograr diluir sus sentimientos y conseguir que el Príncipe se case con Silvia. Hace desfilar ante la pareja aldeana una serie de tentaciones en forma de objetos o de personas para hacerlos entrar en razón y que compren- 
dan todo lo que ganarían aceptando la voluntad del Príncipe, ante los que, en principio, no ceden. Sin embargo, en cuanto dejan de sentirse perseguidos y coaccionados en palacio -tal como Flaminia, convertida en confidente y "protectora" de la pareja, pensaba, - Silvia y Arlequin van apreciando las ventajas materiales de la vida en la corte. Al mismo tiempo, Silvia se irá poco a poco enamorando del amable oficial, aunque ignora que en realidad se trata del Príncipe, y Arlequin apreciará más y más intensamente a Flaminia. En definitiva, los dos aldeanos acaban por sentir como un obstáculo para la propia felicidad los lazos que les unen, sucumben a las tentaciones de la vida en la corte y a sus nuevos amores y la pareja se destruye, de ahí el título de la comedia. El disfraz le permite al Príncipe darse a conocer sin los prejuicios que su verdadera identidad conllevarían para Silvia, como le explica a la aldeana:

Le Prince. Je vous ai jusqu'ici caché mon rang, pour essayer de ne devoir votre tendresse qu'à la mienne: je ne voulais rien perdre du plaisir qu' elle pouvait me faire. A présent que vous me connaissez, vous êtes libre d'accepter ma main et mon cœur, ou de refuser l'un et l'autre. Parlez, Silvia.

Silvia. Ah, mon cher Prince! j'allais faire un beau serment; si vous avez cherché le plaisir d'être aimé de moi, vous avez bien trouvé ce que vous cherchiez. (III, 9)

Dos personajes ocultan su identidad en Le Prince travesti (1724): el príncipe de León, disfrazado de un joven aventurero llamado Lélio, y el rey de Castilla, que se hace pasar por su embajador. El príncipe de León recorre el mundo con el propósito de adquirir la experiencia necesaria para gobernar el día que sea rey: "Depuis que j’ai quitté les États de mon père, et que je voyage sous ce déguisement pour hâter l'expérience dont j'ai besoin si je règne un jour, je n'ai fait nulle part un séjour si long qu'ici'(I, 5). Por su parte, el rey de Castilla utiliza su disfraz para poder conocer con mayor libertad a la mujer que puede convertirse en su futura esposa, de la que se ha enamorado al ver su retrato en miniatura. Le ha pedido matrimonio a través de su embajador, que no es otro que el propio rey disfrazado, que no olvida los intereses políticos de la unión y deja entrever su rango cuando habla con Lélio: "Doucement, vous ne savez pas à qui vous parlez. [...] Laissez-là ce que vous êtes, et soyez sûr que vous me devez respect" (II, 8). Para Frédéric, ministro de la Princesa, sus comentarios son reveladores y quizás no es quien dice ser: "La manière dont vous venez de lui parler me fait présumer bien des choses; peut-être sous le titre d'Ambassadeur nous cachez-vous [...]" (II, 9).

Lélio, a pesar de no olvidar a Hortense, a la que la salvó de unos ladrones que asaltaron su comitiva cuando iba de viaje, está dispuesto a casarse con la Princesa, ya que la soberana se ha enamorado de él por su mérito, no por quién es, pues desconoce su verdadera identidad. Por otra parte, los celos de la soberana nublan por un momento su sentido del honor y actúa de manera deshonesta enviando una falsa notita a su amiga Hortense a través de Arlequin como si fuera de la parte de su señor Lélio (III, 2). La respuesta de Hortense cambia la actitud de la Princesa, pasando de la amistad a la venganza. La comedia termina cuando la Princesa, haciendo gala de su indulgencia, y escuchando la petición del falso embajador de 
Castilla para que perdone a Lélio, renuncia al corazón de éste, permitiendo que él y Hortense se casen. El rey de Castilla y Lélio se quitan sus máscaras y la Princesa concede su mano al benevolente soberano: "Vous, seigneur! Ma main est bien due à un prince qui la demande de manière si galante et si peu attendue" (III, 11). Modelos de gobernantes justos, Lélio y el rey de Castilla anteponen los méritos personales al rango y su disfraz les permite darse a conocer y conocer a los demás con mayor libertad sin que interfiera el prestigio del propio rango.

Éraste, cuya llegada anuncia su criado Crispin, obtiene la aprobación del padre de su prometida en Le Dénouement imprévu (1724) al explicarle que pretende ocultar su identidad haciéndose pasar por un amigo suyo para evaluar la disposición de la señorita Argante ante su matrimonio, impuesto al fin y al cabo: "Monsieur, tout le monde me dit que Mademoiselle Argante est charmante [...] quand je demande à la voir sous cet habit-ci, ce n'est pas pour vérifier si ce que l'on m'a dit est vrai; mais peut-être, en m'épousant, ne fait-elle que vous obéir; cela m'inquiète (esc. IX). Sabemos que la ropa que utiliza para disfrazarse es de color negro, como apunta Maître Pierre, granjero del señor Argante: "De queu vacation êtes-vous avec cet habit noir? Est-ce praticien ou médecin? Tâtez-vous le pouls ou bian la bourse? Dépêchez-vous le corps ou les bians?" (esc. X). Maître Pierre confiesa al que cree amigo de Éraste (que no es otro que él mismo) que la señorita Argante está enamorada de Dorante y, siguiendo el plan que éste le propone, va a fingir estar loca para evitar el matrimonio. Cuando por fin la joven se encuentra con Éraste disfrazado, intenta poner en práctica su estrategia, pero, al mismo tiempo, se enamora de él, adivinando por sus palabras que es Éraste, y no un amigo del mismo, como dice ser:

Éraste. Ma commission est faite, Madame; je sais vos sentiments, dispensez-vous du
désordre d'esprit que vous affectez; un cœur comme le vôtre doit être libre, et mon ami
sera au désespoir de l'extrémité où la crainte d'être à lui vous a réduite. On ne saurait
désapprouver le parti que vous avez pris: l'autorité d'un père ne vous a laissé que cette
ressource, et tout est permis pour se sauver du danger où vous étiez: mais c'en est fait:
livrez-vous au penchant qui vous est cher, et pardonnez à mon ami les frayeurs qu'il
vous a données; je vais l'en punir en lui disant ce qu'il perd.
Il veut s'en aller.
Mademoiselle Argante, à part. Oh, oh! c'est assurément là Éraste. (esc. XI)

En La Mère confidente (1735), Dorante no se atreve a pedir la mano de Angélique pues, aunque ambos tienen origen noble, la joven es rica y Dorante carece de fortuna, razón por la cual teme ser rechazado por la madre pues, aunque los jóvenes no consideren que la falta de dinero sea un obstáculo para su amor, la madre de Angélique sí, y le propone a la joven un pretendiente rico, Ergaste, tío de Dorante: "quand une fille est riche, on ne la donne qu'à un homme qui a d'autres richesses, toutes inutiles qu'elles sont; c'est, du moins, l'usage, le mérite n'est compté pour rien" (II, 12). La solución de Dorante es huir para poder estar juntos y, la señora Argante, al enterarse, le propone a su hija asistir a su cita clandestina y hacerse pasar por una tía suya para hablar con él y convencerlo de que su plan de huir con la 
joven es peligroso e insensato: "Eh bien! laisse-moi le voir, je lui parlerai sous le nom d'une tante à qui tu auras tout confié, et qui veut te servir; viens, ma fille, et laisse à mon cœur le soin de conduire le tien" (II, 12). El disfraz le permitirá descubrir quién es Dorante, dejando a un lado sus prejuicios, pues, cuando le aconseja que no lleve a cabo la locura de fugarse con su hija, decisión que dañaría para siempre la reputación de la joven, Dorante renuncia a su propósito, no quiere perjudicar a su amada, al contrario, prefiere perderla antes de lastimarla:

Dorante. N'en doutez pas, ma chère Angélique: oui, je me rends, je la désavoue: ce n'est pas la crainte de voir diminuer mon estime pour vous qui me frappe, je suis sûr que cela n'est pas possible; c'est l'horreur de penser que les autres ne vous estimeraient plus, qui m'effraye; oui, je le comprends, le danger est sûr, Madame vient de m'éclairer à mon tour: je vous perdrais, et qu'est-ce que c'est que mon amour et ses intérêts, auprès d'un malheur aussi terrible? (III, 11)

Las palabras de Dorante conmueven a la madre de Angélique, que descubre su identidad y acepta el matrimonio de su hija con un hombre tan bondadoso: “j'accorde ma fille à Dorante que vous voyez. Il n'est pas riche, mais il vient de me montrer un caractère qui me charme, et qui fera le bonheur d'Angélique" (III, 12): Del mismo modo, Ergaste, tío de Dorante, renuncia a su matrimonio con Angélique y decide enriquecer a su sobrino en vida: "Je vais vous le dire, Madame, c'est mon neveu, le jeune homme dont je vous parle, et à qui j'assure tout mon bien" (III, 12).

\section{3. Épreuves}

Marivaux utiliza el disfraz en las comedias que F. Deloffre y F. Rubellin denominan en su clasificación de las comedias de Marivaux épreuves, aquellas que muestran "comment on peut éprouver la sincérité d'un amour" (2000: 15), englobando bajo esta rúbrica Le Jeu de l'amour et du hasard (1730), L'Épreuve (1740) y La Femme fidèle (1755).

En Le Jeu de l'amour et du hasard (1730), la profunda desconfianza que Silvia siente hacia los hombres hace que solicite a su padre la posibilidad de hacerse pasar por su criada Lisette para poder observar las cualidades y defectos de su futuro marido, al que no conoce, sin que éste se dé cuenta. El padre de Silvia está de acuerdo y a la joven le basta con un delantal para hacerse pasar por su criada Lisette: "Il ne me faut presqu'un tablier" (I, 5). Lo que no sabe es que su prometido, Dorante, temeroso también ante el matrimonio, ha solicitado a su vez permiso para proceder de la misma manera e intercambiarse con su criado Arlequin, tal y como le dice en su carta el padre de Dorante al señor Orgon, carta que le lee al hermano de Silvia, Mario, también de acuerdo con el plan: “il faudra bien qu'ils se parlent souvent tous deux sous ce déguisement, voyons si leur cœur ne les avertirait pas de ce qu'ils valent”(I, 4). Marivaux señala el disfraz de Dorante a través de una didascalia: "Dorante, en valet" (I, 6). Por su parte, Arlequin, aunque convertido en noble, es grosero, a pesar de las recomendacio- 
nes de su señor, que lo regaña: “Tu m’avais tant promis de laisser là tes façons de parler sottes et triviales, je t'avais donné de si bonnes instructions, je ne t'avais recommandé que d'être sérieux" (I, 10). El falso Dorante provoca la repulsión de Silvia, que no comprende cómo Lisette es capaz de soportarlo: "Je vous trouve admirable de ne pas le renvoyer tout d'un coup, et de me faire essuyer les brutalités de cet animal-là”,(II, 7). El disfraz les permite ser más espontáneos y enamorarse de los méritos personales del otro, sin tener en cuenta el rango, pues ambos creen que el otro es un criado. Dorante es el primero en quitarse la máscara y en confesar a Silvia su verdadera condición:

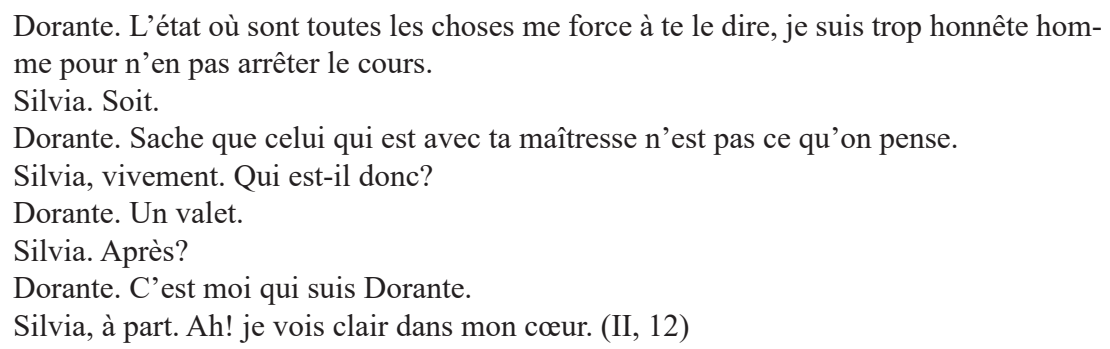

No hay ninguna razón para que Silvia siga ocultando su identidad. Sin embargo, el objetivo de la joven, que justifica enteramente la existencia del tercer acto de la obra, es explícito, es la prueba a la que quiere someter a Dorante para comprobar si su amor es tan fuerte como para que le proponga matrimonio, a pesar de ser una simple criada: "Dans Le Jeu de l'amour et du hasard, Silvia, fille de qualité, demande à un modeste costume de soubrette de lui apprendre les sentiments véritables de Dorante à son égard" (Catsiapis, 1979: 69-70). La joven alcanza su objetivo y Dorante le propone matrimonio creyendo que es una criada, sin importarle ni su rango ni su fortuna. La pareja se atrae por sus méritos personales, por tanto, Marivaux reivindica un orden de valores distinto al establecido, él valora una nobleza moral, no las circunstancias del rango:

Silvia. Quoi, vous m'épouserez malgré ce que vous êtes, malgré la colère d'un père, malgré votre fortune?

Dorante. Mon père me pardonnera dès qu'il vous aura vue, ma fortune nous suffit à tous deux, et le mérite vaut bien la naissance: ne disputons point, car je ne changerai jamais. Silvia. Il ne changera jamais! Savez-vous bien que vous me charmez, Dorante? (III, 6)

En L'Épreuve (1740) Lucidor, enamorado de Angélique, cuyo rango y fortuna son inferiores a los suyos, pretende comprobar si la joven lo quiere por sus méritos o por su dinero. Para poner a prueba el interés de Angélique, le presenta a su criado Frontin, disfrazado de rico hombre de negocios, como un posible marido que puede asegurar su porvenir. Frontin aparece disfrazado desde la primera escena "en bottes et en habit de maître" siguiendo las instrucciones que Lucidor le ha dado a través de una carta: 
Frontin. Je viens de mettre pied à terre à la première hôtellerie du village, j'ai demandé le chemin du château suivant l'ordre de votre lettre, et me voilà dans l'équipage que vous m'avez prescrit. De ma figure, qu'en dites-vous? (il se retourne.) Y reconnaissezvous votre valet de chambre, et n'ai-je pas l'air un peu trop seigneur? (esc. I)

Por otra parte, Lucidor utiliza los objetos para llevar a cabo su plan, destacando las joyas y un retrato en miniatura de una mujer, que resulta ser su hermana. Todas las pruebas suponen un tremendo dolor para Angélique, que estaba convencida del amor de Lucidor, aunque no se lo hubiera declarado explícitamente. La joven supera, no sin sufrimiento, la prueba que le pone su amado. La recompensa es la declaración de amor de Lucidor. La estrategia que ha utilizado sorprende a la joven que, dolida por lo que ha tenido que pasar y, al mismo tiempo, contenta por lo que acaba de oír, insinúa que ella no lo hubiera puesto a prueba de esa manera: "si jamais je viens à aimer quelqu'un, ce ne sera pas moi qui lui chercherai des filles en mariage, je le laisserai mourir plutôt garçon" (esc. XXI).

Por último, en La Femme fidèle (1755), el Marqués, al que todos creen muerto, y su criado Frontin, se disfrazan de dos viejos prisioneros llegados de Argelia que han compartido cautiverio con el Marqués y traen noticias suyas a la Marquesa: "Le Marquis, Frontin, en captifs " (esc. I). El disfraz no logra engañar al jardinero Colas, que los reconoce, a pesar de las barbas postizas: “[...] Eh! palsangué, Monsieur! ...c’est encore vous! C'est Monsieur le Marquis, c'est Frontin; je me moque des barbes, ce n'est que des manigances" (esc. II). Con el disfraz, el Marqués pretende conocer los sentimientos de su esposa, pues, creyendo que su marido ha muerto, se va a volver a casar: "et malgré cette longue absence, je reviens toujours plein d'amour pour elle, fort en peine de savoir si ma mémoire lui est encore chère, et c'est avec l'intention de prouver ce qui en est que j'ai pris ce déguisement" (esc. II). Lo que no sabe el Marqués es que el nuevo matrimonio ha sido orquestado por su suegra, que ha coaccionado a la Marquesa para que aceptara casarse con Dorante haciéndole creer que su marido ha muerto mediante un falso certificado de defunción del Marqués, llegado supuestamente desde Argelia. Con el fin de poner a prueba el amor de su mujer, el Marqués se servirá de dos objetos, cuyo valor simbólico y afectivo conseguirá desvelar el amor de la supuesta viuda, un retrato en miniatura y una carta. Al descubrir que su marido ha conservado la última prueba que le dio de su afecto, su retrato en miniatura, la Marquesa llora emocionada y decide quedarse con su imagen y no entregársela a Dorante, cumpliendo la voluntad del difunto. En cuanto a la carta, cuando el Marqués consigue por fin quedarse a solas con su mujer para entregarle su propia carta, ésta le confiesa que se casa con Dorante para cumplir la promesa que le hizo a su madre. La reacción que provoca la carta en la Marquesa es la prueba definitiva de su amor incondicional por el Marqués, pues, al saber que su marido seguía vivo cuando se la entregó a su amigo, decide suspender la boda y buscarlo: "déjà je romps tout: plus de mariage! Mais de quel côté irait-on? Quelles mesures prendre? Où pourrait-on le trouver?" (esc XVI). En ese momento, el Marqués decide quitarse el disfraz y descubrirse 
Anales de Filología Francesa, n. ${ }^{\circ} 28,2020$

¿ILUSión o REALIDAD? El DisfraZ EN Las COMEdias de MarivauX

ante su mujer: "Le Marquis, ôtant sa barbe et se jetant à ses genoux: Non, je vous suis aussi cher qu'il vous l'est lui-même" (esc XVI).

\subsection{Lección moral}

A través del disfraz, los personajes pueden conseguir desenmascarar a otro personaje, castigarlo por su comportamiento y, al mismo tiempo, transmitir una lección moral, como ocurre en cuatro de las comedias analizadas.

En La Fausse Suivante ou Le Fourbe Puni (1724), el punto de partida del enredo es el disfraz de caballero que lleva puesto la damisela de París en un baile de máscaras al que acude con sus amigas. Inesperadamente, encuentra a Lélio, su futuro marido, al que no conoce. El joven no se da cuenta de que es una mujer y se hacen amigos. La dama aprovecha la oportunidad que le ha brindado la suerte para conocerlo. El disfraz de caballero exige que la dama lleve una espada, objeto que descubrimos cuando la joven intenta desenfundarla al sentirse ofendida por Trivelin, pero éste le recuerda que no es propio de su sexo manejarla: "Fi! ne gesticulez point de cette manière-là; ce geste-là n'est point de votre compétence; laissez là cette arme qui vous est étrangère: votre œil est plus redoutable que ce fer inutile qui vous pend au côté" (I, 3). A pesar de intentar comprar el silencio de los criados, el secreto del Caballero pasa de Frontin a Trivelin y de éste a Arlequin, que hace llegar el rumor a oídos de Lélio: Cuando éste descubre que su amigo el Caballero es, en realidad, una mujer, la damisela de París decide hacerse pasar por una criada al servicio de la mujer con la que se ha comprometido Lélio, cuya misión era disfrazarse para poder espiarlo y transmitir sus impresiones a su señora, dando título a la comedia:

\footnotetext{
Le Chevalier. Par cette mission-là, c'est une tendre brebis qui échappe au loup, et douze mille livres de rente de sauvées, qui prendront parti ailleurs; petites, bagatelles qui valaient bien la peine d'un déguisement. [...] Je m'explique: la brebis, c'est ma maîtresse; les douze mille livres de rente, c'est son bien, qui produit ce calcul si raisonnable de tantôt. Et le loup qui eût dévoré tout cela, c'est vous, Monsieur. [...] On a su que vous étiez à Paris incognito; on s'est défié de votre conduite. Là-dessus on vous suit, on sait que vous êtes au bal; j'ai de l'esprit et de la malice, on m'y envoie; on m'équipe comme vous me voyez, pour me mettre à portée de vous connaître; $j$ 'arrive, je fais ma charge, je deviens votre ami, je vous connais, je trouve que vous ne valez rien; j'en rendrai compte; il n'y a pas un mot à redire. (III, 5)
}

La damisela disfrazada de caballero descubre que el único interés que muestra su futuro marido por las mujeres a las que corteja es su dinero, así que decide seguir con el disfraz para darle un escarmiento. Los personajes que fingen amor por interés y anteponen su avaricia a sus propios sentimientos son condenados y castigados por Marivaux en sus comedias: el descubrimiento de la verdadera identidad del Caballero termina con los planes de Lélio (se destruyen los dos posibles matrimonios de conveniencia) y con el amor de la Condesa. 
Desde la primera escena de L'Île des esclaves (1725), la espada y la botella identifican respectivamente a los personajes de Arlequin ("avec une bouteille de vin qu'il a à sa ceinture") y de Iphicrate ("au désespoir, courant après lui l'épée à la main"). La espada en la época es el símbolo de la nobleza, y es Iphicrate quien la lleva a la cintura, al igual que Arlequin lleva su botella. Los naúfragos, obligados por Trivelin, gobernador de la isla, tienen que cumplir la ley: empezando por intercambiar sus nombres y sus ropajes (se disfrazan, en cierto modo, del otro), invierten su relación de poder (y su rango social, pasan de noble a criado, y viceversa) para que los señores sufran lo que les han hecho padecer a sus esclavos y puedan ser merecedores de su libertad corrigiendo su actitud. Tras ordenar que desarmen a Iphicrate, Trivelin “prend l'épée d'Iphicrate et la donne à Arlequin” (esc. II). La lección de Marivaux queda clara: únicamente por la superación del egoísmo y del rencor, la convivencia puede alcanzar la concordia. No se trata, por lo tanto, de una mera sustitución de individuos que repitan en su nueva situación los mismos pecados, sino del necesario aprendizaje de unos $\mathrm{y}$ otros de ver en todo individuo a un semejante, a pesar de las desigualdades imperantes. Si bien en las comedias no se cambia el orden social establecido, se modifica, en palabras de M. T. Ramos "la actitud hacia el otro" (2005: 501), y los personajes tienen que pasar obligatoriamente por esa terapia con el fin de dejar paso a la conciencia afectiva. Por ello, al final de la comedia, Arlequin y Cléanthis deciden perdonar a sus señores y les devuelven sus ropajes $\mathrm{y}$, con ellos, su posición (esc. XI).

Plutus desafía a Apollon en Le Triomphe de Plutus (1728), afirmando que sería capaz de conquistar a Aminte sólo con sus riquezas, sin tener que recurrir ni a los pœmas ni a los modales de su rival. La apuesta está servida. Los dioses se disfrazan de mortales y se esconden tras los nombres de Ergaste (Apollon) y Richard (Plutus). Plutus sobornará a los criados, al tío de Aminte y a ella misma y cambiará el curso de los acontecimientos, usurpando a Ergaste el corazón de Aminte, ganando la apuesta que ambos dioses habían hecho y demostrando, como resume Apollon, que "l'or est la seule divinité à qui les hommes se sacrifient" (esc. XVII). En esta comedia, Marivaux demuestra que la riqueza compra voluntades e incluso pervierte a criados y a señores, convirtiéndose en el hilo conductor de la acción y no duda en denunciar cómo corrompen el corazón humano.

La inexperiencia de Damon en La Joie imprévue (1738) hace que pierda una importante suma de dinero apostando, la mitad de lo que su padre le había dado para comprar un cargo, motivo de su viaje a París. Desobedece, pues, sus órdenes, y cae en las redes del Caballero, que lo embauca para jugar una vez más, ante la desesperación de su criado Pasquin. Abocado al fracaso, su benevolente padre se las ingenia para hacerse pasar por el Caballero y así evitar que el joven pierda su dignidad y el dinero que le queda. Para ello, el señor Orgon se disfraza, ayudado por Pasquin, con un domino del mismo color que el del Caballero que va a jugar con su hijo, pues la noche de la partida hay un baile de máscaras en el hotel, circunstancia que aprovecha para jugar contra Damon sin que lo reconozca: "M. Orgon, en 
domino pareil à celui que, suivant l'instruction de Pasquin, doit porter le Chevalier" (esc. XVII). Marivaux presenta, pues, un modelo de padre comprensivo que, preocupado por la educación de su joven hijo, le deja cometer sus propios errores para que aprenda mediante su experiencia los peligros que conlleva un vicio como el juego, que no sólo lo perjudicaría a él en primera persona, sino también a su familia:

\begin{abstract}
Monsieur Orgon. [...] il est jeune, il a fait une faute, il n'y a rien d'étonnant, et je la lui pardonne, pourvu qu'il la sente; c'est ce qui décidera de son caractère: ce sera un peu d'argent qu'il m'en coûtera, mais je ne le regretterai point si son imprudence le corrige $[\ldots]$

Monsieur Orgon. Le Chevalier et lui seront-ils masqués?

Pasquin.- Je n'en sais rien, mais je crois qu'oui, car il y a quelques jours qu'il y eut ici un bal où ils étaient tous deux; mon maître a même encore son domino vert qu'il a gardé pour ce bal-ci et je pense que le Chevalier, qui loge au même hôtel, a aussi gardé le sien qui est jaune. (esc. VI)
\end{abstract}

\title{
2.5. Otros usos del disfraz
}

Tres comedias escapan a las funciones anteriores, Le Père prudent et équitable ou Crispin l'Heureux Fourbe (1712), La Méprise (1734) y La Commère (1741).

El propósito de Crispin en Le Père prudent et équitable (1712) es ayudar a su señor Cléandre, pues Démocrite, el padre de su amada Philine, no quiere que se casen, ya que la fortuna de Cléandre se encuentra comprometida en juicios, y le propone a su hija tres pretendientes. Para provocar el rechazo entre el suegro y los pretendientes, Crispin se hará pasar sucesivamente por Démocrite (“Crispin, s'entortillant le nez dans son manteau”, esc V), por el rico campesino Ariste ("Crispin, contrefaisant Ariste”, esc. XII) y por una mujer ("Crispin, déguisé en femme”, esc. XXI). Contará con la ayuda de la criada Toinette, que interpretará, siguiendo sus órdenes, el papel de una descarada Philine ("Fais ton rôle, entends-tu? je te nomme ma fille", esc. VI) y de Frontin, que se disfrazará de un hombre de negocios ("Frontin arrive, contrefaisant le Financier", esc. XIX).

En cambio, en La Méprise (1734), el disfraz es involuntario, pues la máscara aparece como un objeto utilitario que usan las damas de la zona para protegerse del sol durante los paseos en verano, como explica Lisette a Frontin: “en ce pays-ci, c'est l' usage en été, quand on est à la campagne, à cause du hâle et de la chaleur" (esc. II). Sin embargo, de manera inconsciente en este caso, la máscara también oculta la identidad de las hermanas Clarice y Hortense. La didascalia con la que da comienzo la cuarta escena resulta indispensable para explicar la confusión a lo largo de la obra, pues Ergaste, sin saberlo, va a cortejar a la vez a las dos, creyendo que son una sola persona, pues ambas llevan puesta la misma ropa y sus rostros cubiertos por máscaras para protegerse del sol: 
Hortense, quand elle entre sur le théâtre, tient son masque à la main pour être connue du spectateur, et puis le met sur son visage dès que Frontin tourne la tête et l'aperçoit. Elle est vêtue comme l'était ci-devant la dame de qui Ergaste a dit avoir ramassé le gant le jour d'auparavant, et c'est la sœur de cette dame. (esc. IV)

Por su parte, la solterona señorita Habert, protagonista de La Commère (1741) utiliza el disfraz para intentar transformar a Jacob, un pastor de Borgoña que trabajó en su casa como copista, con el que se quiere casar en secreto, a pesar de la diferencia de edad y de condición, pues su familia se opone, en especial, un sobrino. Lo ha vestido con buenos ropajes, le ha enseñado buenos modales e incluso le ha cambiado el nombre, aunque no por ello deja de ser un aprovechado que busca enriquecerse con su matrimonio:

La Vallée. Pardi, je vois des bontés qui sont des merveilles! Je vois que vous avez levé un habit qui me fait brave comme un marquis; je vois que je m'appelais Jacob quand nous nous sommes connus, et que depuis quinze jours vous avez eu l'invention de m'appeler votre cousin, Monsieur de La Vallée. Est-ce que cela n'est pas admirable? (esc. I)

\section{Conclusión}

Como acabamos de ver, el uso del disfraz otorga a los personajes marivaldianos una identidad prestada para conseguir sus propósitos, fundamentalmente, allana los obstáculos espaciales, permite conocer a los demás con mayor libertad e incluso escarmentar a otro personaje. A pesar de que Marivaux condena el engaño y las mentiras en sus obras, en su incesante búsqueda de la verdad, la transgresión de los códigos vestimentarios y la utilización de los disfraces se aceptan si la motivación de dicho acto es noble.

$\mathrm{Su}$ importancia en la escritura dramatúrgica de Marivaux radica en la dependencia que de él manifiesta la intriga en las comedias en las que aparece: la acción puede nacer a partir de un disfraz, modificarse gracias a él o terminar debido a él. Puede, en consecuencia, ser el punto de partida de una comedia, condicionar una parte o la totalidad de la intriga, convertirse en adyuvante u obstáculo para el desarrollo de la acción, dar lugar a quiproquos (motivados por las sucesivas y distintas interpretaciones que les dan los personajes) o poner fin a la obra. Aunque a veces su función primera sea encubrir la realidad, al final consiguen revelar la verdad. Marivaux los utiliza para materializar el conflicto interno del personaje, hacer reflexionar al espectador y, al mismo tiempo, transmitir una lección moral, anteponiendo los valores humanos a los valores sociales.

El valor del disfraz es indiscutible en la estrategia amorosa. Marivaux lo maneja con maestría consiguiendo incluso una triple identidad en dos de sus comedias, La Fausse Suivante (1724) y Le Triomphe de l'amour (1732), dando lugar a múltiples enredos. Como afirma Cléandre en la última escena de Le Père prudent et équitable (1712): "Je me suis, il est 
vrai, servi de stratagème; Mais que ne fait-on pas, pour avoir ce qu'on aime?" El dramaturgo hace que los disfraces se transformen en reveladores de sentimientos hasta el momento ocultos para los personajes, pongan a prueba los suyos y provoquen una reacción afectiva en ellos, que, a su vez, puede conllevar la ejecución o no de una acción posterior. Frente al matrimonio basado en el interés, Marivaux reclama en sus comedias un matrimonio sincero, basado en el amor y en el respeto mutuo, condenando el fingir amor por interés. La psicología de los personajes está, pues, tratada con dinamismo en su camino hacia la verdad y la lucidez. Es un juego de relaciones entre su "yo" social y su "yo" personal, en el que tienen cabida la mentira y el disfraz, entendiéndolos como la imagen que los personajes quieren transmitir y no sus verdaderos sentimientos. Esto es precisamente lo que hay que vencer para llegar a la lucidez y a la sinceridad:

Ce qui intéresse Marivaux, c'est la phase initiale de l'amour, lorsqu'il émerge à la conscience dans une atmosphère "de trouble, de plaisir et de peur", comme le dit Marianne. Du moment où, l'âme saisie de vertige, le personnage se dit "je ne sais où j'en suis", jusqu'au moment où, enfin éclairé, il murmure "je vois clair dans mon cœur", depuis la découverte encore inconsciente de l'amour jusqu'à l'acquiescement à l'amour, tel est le cheminement que l'auteur prétend suivre et restituer. Mais, pour en faire une matière dramatique, des incidents sont nécessaires, et un mode d'expression doit être inventé. (Deloffre \& Rubellin, 2000: 8)

En sus comedias sociales (igualmente psicológicas), la temática principal es el entendimiento: el autor reivindica unas relaciones auténticamente humanas para poder hablar de una sociedad justa, mostrando que lo humano ha de prevalecer sobre lo social. A lo largo de la acción de la comedia, a través de las pruebas que la situación les plantea, algunos personajes logran rehabilitarse, aprendiendo una lección de humanidad que les permite descubrir la injusticia de su comportamiento, lo desnaturalizado de su trato con los otros, como ocurre en L'Île des esclaves (1725). Y aunque los personajes no siempre alcancen esa lucidez, son los espectadores los destinatarios de esa lección.

Las situaciones que el autor crea en cada una de sus comedias enmascarando la identidad de sus personajes permiten analizar el comportamiento habitual entre los miembros de una sociedad jerárquica, y proponer otra actitud frente al prójimo, pues Marivaux aborda las relaciones humanas desde una perspectiva moral, se interesa por el comportamiento entre individuos y no cuestiona la sociedad en que vive, sino las relaciones entre los seres humanos. El disfraz de Marivaux es, por tanto, transitorio y las comedias terminan cuando se desvela la verdadera identidad del personaje: "Dans les comédies de Marivaux, chacun, après une parodie délicieuse de déstabilisation, reprend son costume, sa robe et sa perruque, et surtout sa fonction, son rang et ses titres. Ce ne sont pas là des conventions, mais des déterminations nécessaires" (D’Hondt, 1991:104). El sentimiento se confiesa (a uno mismo y a los demás) y 
el lenguaje de las palabras coincide con el lenguaje espontáneo del corazón (Pomeau, 1971: 189).

Las comedias que acabamos de analizar perderían su razón de ser sin la presencia de los objetos que utilizan los personajes para ocultar su identidad. El disfraz se materializa en la simplicidad de objetos cotidianos que le permiten al dramaturgo acercar a los espectadores a la acción que se desarrolla en escena, utilizándolos incluso como hilo conductor de la misma. Así pues, a pesar de las restricciones materiales de la puesta en escena de la época, asistimos a una normalización del uso del disfraz en las comedias marivaldianas. Si hubiese que resumir en una sola palabra todas las posibilidades que el disfraz proporciona tanto a los personajes de Marivaux como al propio autor, bastaría con decir libertad:

Je parlerais d'un théâtre français au milieu du XVIII ${ }^{e}$ siècle; je parlerais du théâtre de Marivaux. [...] des différentes différences, de personnes, de sexes, de générations, de conditions sociales et des espèces variées des doubles; de la malédiction sociale (différences entre grands et bourgeois et serviteurs et paysans) et de la conjuration heureuse de cette malédiction par la subversion expérimentale, "théorique", en représentation théâtrale, utopique, des différences, qui se résout dans la restitution du même autour du pivot de la tendresse ainsi révélé; et du bon rapport de dédoublement-redoublement des maîtres et des valets, modèles réciproques; de la fiction de l'épreuve comme épreuve de la fiction, par quoi le malentendu apparaît surmontable. Méprise, stratagème, surprise, travesti, duperie, fourberie: machination dramatique: machinerie du frein et de la précipitation, du retard et de la hâte; chance, aléa, risque, enjeux, gains". (Déguy, 1981: 47-48)

\section{Referencias bibliográficas}

BOBES NAVES, Ma Carmen. 1988. Estudios de semiología del teatro. Valladolid, Aceña Editorial.

Catsiapis, Hélène. 1979. "Les objets au théâtre" in Communication et langages, nº43, 59-78.

DÉGUY, Michel. 1981. La machine matrimoniale ou Marivaux. Paris, Gallimard.

Deloffre, Frédéric. 1993. Une préciosité nouvelle. Marivaux et le marivaudage. Genève, Slatkine Reprints.

D’Hondt, Jacques. 1991. "Marivaux, le masque, l'habit et l'être” in Bulletin de la Société Américaine de Philosophie de Langue Française, vol. 3, nº 2, 95-105.

FORESTIER, Georges. 1988. Esthétique de l'identité dans le théâtre français (1550-1680). Le déguisement et ses avatars. Genève, Droz.

JimÉNEZ-SALCEDO, Juan. 2008.“Travestissement féminin et guerre des sexes dans l'œuvre de Marivaux" in Revue des Sciences Humaines, nº 291, 173-180.

Kowzan, Tadeusz. 1968. "Le signe au théâtre. Introduction à la sémiologie de l'art du spectacle" in Diogène, n68, 59-90. 
Anales de Filología Francesa, n. ${ }^{\circ} 28,2020$

¿ILUSión o ReALIDAD? El DisfraZ en las COMEdias de MarivauX

LAFOn, Henri. 2012. Les Décors et les choses dans le roman français du XVIII siècle, de Prévost à Sade. Oxford, Voltaire Foundation University of Oxford, SVEC.

Lambert, Pauline. 1973. Realité et ironie: Les jeux de l'illusion dans le théâtre de Marivaux, Fribourg/Suisse, Editions universitaires.

Marivaux, Pierre Carlet (de). 2000. Théâtre complet. (Édition de F. Deloffre et F. Rubellin). Paris, La Pochothèque/Classiques Garnier.

NaKaYAma, Tomoko. 2002. "La fonction dramaturgique du travestissement des femmes en homme dans les pièces de l'Ancien Théâtre Italien" in Études de Langue et Littérature françaises de l〉Université de Hiroshima, n² 21, 19-28.

PAvis, Patrice. 1986. Marivaux à l'épreuve de la scène. Paris, Publications de la Sorbonne.

Pavis, Patrice. 2005. L'analyse des spectacles. Paris, Armand Colin.

Peyronnet, Pierre. 1974. La Mise en scène au XVIII siècle. Paris, Nizet.

Pomeau, René. 1974. "Pour une dramaturgie de Marivaux" in Pappas, John (ed.). Essays on Diderot and the Enlightenment in honor of Otis Fellows. Génève, Droz, 256-267.

Ramos Gómez, María Teresa. 2005. "Utópico Marivaux" in Desprès Caubrière, Catherine(coord.). Homenaje al Profesor D. Francisco Javier Hernández. Valladolid, Universidad de Valladolid, Departamento de Filología Francesa y Alemana, 491-504.

Ramos Gómez, María Teresa. 2009. "La Fausse Suivante, ou la dynamique du triangle” in Revista de Estudios franceses Çédille, nº5, 283-303.

Rousset, Jean. 1989. Forme et signification. Paris, José Corti.

Trotт, David. 2000. Théâtre du dix-huitième siècle. Jeux, écriture et regards. Essai sur les spectacles en France de 1700 à 1790. Montpellier, Espaces 34.

Ubersfeld, Anne. 1993. Semiótica teatral. Madrid, Cátedra.

Vuillermoz, Marc. 2000. Le Système des objets dans le théâtre français des années $1625-$ 1650, Corneille, Mairet, Rotrou, Scudéry. Genève, Droz.

Nakayama, Tomoko. 2001. "Le théâtre de Marivaux et le travestissement" in Études de Langue et Littérature françaises de l>Université de Hiroshima, n 20, 16-28. <http://doi. org/10.15027/19711> [12/06/2020]. 